\title{
Recovering Gas Flares from the 12th Gas Phase of the South Pars Gas Refinery
}

Kiumars Hashemi Farda,*, Mojtaba Shafiee ${ }^{\mathrm{b}}$

a Chemical Engineering-Process Design, South Pars Gas Complex Phase 12, Site 2, Kangan, Iran

${ }^{b}$ Department of Chemical Engineering, Jundishapur Industrial Dezful University of Technology, Khuzestan, Iran

\section{A R T I C L E I N F O}

Received: 9 May 2019

Revised: 10 June 2019

Accepted: 27 June 2019

Available online: 30 June 2019

DOI: $10.33945 /$ SAMI/AJCA.2019.1.6

\section{K E Y W O R D S}

Flare gas

Economic value

Electrical energy

Equivalent volume

\section{A B S T R A C T}

In this study, the economic value of flared gases in gas phase 12 gas refinery was investigated. The economy itself has been examined from two perspectives. The first view on the conversion of fired gases to electrical energy and its revenue generation using the McLaren method. In the second view, the volume of flared gases is equivalent to the amount of gas consumed in industries, households and exports. According to the results, the gross profit from flaring gas to electric energy was $\$ 123,125$ per year. The volume of flared gases was equivalent to the consumption volume of power plants at $0.77 \%$, the equivalent of $3.3 \%$, the consumption volume of the industries was $1.24 \%$, and the domestic and commercial consumption was $0.3 \%$, and it should be noted. Carried out in 2017 and 2018.

GRA PHICALABSTRACT

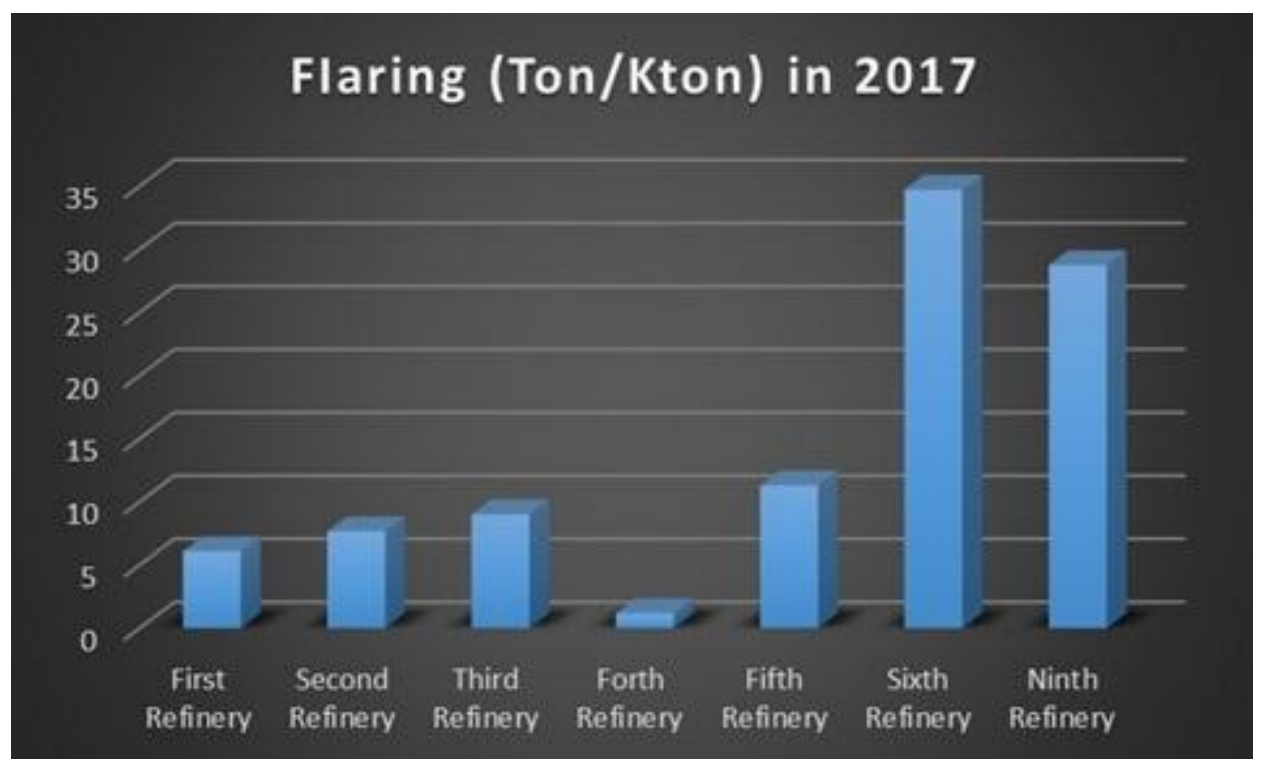

* Corresponding author's E-mail address: kiumars.hf@gmail.com 


\section{Introduction}

Given the growing population and the need for energy, energy consumption is becoming increasingly important, especially nonrenewable energy sources such as oil and gas. Flare gases are considered as one of the sources of energy, which is important in two respects: economic value and emissions from burning flares. In this regard, considering that flare gases contain specific compounds and flow rates, it is necessary to decide how to recover them, analyze them and determine the amount of flux. As noted, flare gases need to be restored and recovered for two reasons: one is economic value, the second is pollutant. The first reason is that many flared gases contain valuable materials such as methane, which have a high value in terms of thermal and industrial and domestic consumption. The second reason is the contamination problem that was created after burning flare gases. When these gases are burnt, other harmful gases, such as $\mathrm{CO}_{2}, \mathrm{CO}, \mathrm{NO}_{\mathrm{x}}$ and $\mathrm{SO}_{\mathrm{x}}$, are produced mainly by gases that have no harmful effects on the environment. Therefore, it is imperative that these gases return to the cycle. According to the World Bank, 150 billion cubic meters of gas are flooded annually, and Iran is the third largest country, according to another report from the same organization, $\mathrm{CO}_{2}$ emissions from flooding of these gases are 400 million tons annually, the burned flare is equivalent to gas consumption in Germany and France. Here I will introduce the methods used to recover flare gases:

1. Generate LNG and use this product.

2. Direct electricity production by turbo generators.

3. Collect and inject gas flares into gas fields or oil reservoirs.

4. Use of methane and carbon dioxide gas and heat from burning gas in GTL production processes.

5. Collecting and transferring it to the gas transmission network and to the natural gas facilities.

Taheri concluded in 2010 that an average of 4000 cubic meters per hour of flood gases in the oil refinery of Imam Khomeini's Phase 2 can be returned to the system after the system for the recovery of flare gases [3].

In 2011, Asare et al., concluded that the highest concentration of pollution caused by flare gases at ground level was based on the numerical model, and in particular the Gaussian model in neutral and fixed conditions [4].

In 2015, Amini concluded that volumetric refueling could be prevented by two methods: the design and installation of a new flare system, and the use of the HIPPS system, the second method being more economical and better [1].

Soltani et al. (2016) concluded that using a spectroscopic sputtering method from the pilot line, the peak oxygen content was high due to high temperature oxidation [5].

\section{Experimental}

Petro Pars, as the main operator, was responsible for the development of Phase 12 of the South Pars gas field for the National Iranian Oil Company. The capacity of the drought facility is 3 billion cubic feet of fluid reservoir per day, of which 2,285 billion cubic feet (MMSCFD) of fresh gas is produced daily for delivery to the global pipeline. In addition to the production of sweetened gas, 120,000 barrels of gas condensate and 750 tons of sulfur per day are also produced from the refinery. The refinery also has six operational gas-washing rows, four operational rows of sulfur gas, 3 the operational row of the gas condensate stabilization unit (103) and the three operational rows of the sulfur granular unit (144). Table 1 shows the amount of discharge into the flare stacks for high pressure lines (HP), medium pressure (MP) and low pressure (LP). Table 2 shows the values of flare gas combinations for high 
pressure lines, medium pressure and low pressure [17].

Table 1. Entry rate based on design values

$\begin{array}{cc}\text { Flare Stachs } & \text { Design Flow Rate (MMSCFD) } \\ \text { HPb } & 1200 \\ \text { MPc } & 200 \\ \text { LPd } & 100\end{array}$

a Million standard cubic foot per day

b High pressure

c Medium pressure

d Low pressure

Table 2. Values of gas flare compounds Phase 12

\begin{tabular}{|c|c|c|c|}
\hline Composition & HP gas & MP gas & LP gas \\
\hline $\mathrm{H}_{2} \mathrm{O}$ & 0.0001 & - & 10.65 \\
\hline $\mathrm{N}_{2}$ & 3.5549 & 3.58 & 0.01 \\
\hline $\mathrm{CO}_{2}$ & 0.8999 & 0.89 & 51.36 \\
\hline $\mathrm{H}_{2} \mathrm{O}$ & 0.0003 & - & 37.41 \\
\hline $\mathrm{H}_{2} \mathrm{~S}$ & 86.9892 & 87.06 & 0.36 \\
\hline Methane & 5.5383 & 5.46 & 0.03 \\
\hline Ethane & 1.9846 & 1.97 & 0.0089 \\
\hline Propane & 0.3213 & 0.32 & 0.00155 \\
\hline$i$-Butane & 0.4606 & 0.47 & 0.0023 \\
\hline$n$-Butane & 0.1074 & 0.12 & - \\
\hline$i$-Pentane & 0.0825 & 0.09 & - \\
\hline$n$-pentane & 0.0435 & 0.07 & 0.0155 \\
\hline $\mathrm{C}_{6}$ & 0.0124 & - & - \\
\hline $\mathrm{C}_{7}$ & 0.0031 & - & - \\
\hline $\mathrm{C}_{8}$ & 0.0031 & - & - \\
\hline $\mathrm{C}_{9}$ & 0.0004 & - & - \\
\hline $\mathrm{C}_{10}$ & 0.0001 & - & - \\
\hline Mercaptans & 0.0011 & - & 0.155 \\
\hline
\end{tabular}

According to the data, it was found that the amount of methane in HP and MP is $87 \%$, which is important in terms of thermal value.

The methods used to rehabilitate and reuse gas flares up to now are briefly explained:
1. Collecting and injecting gas flares into gas fields or crude oil reservoirs to increase pressure in these reservoirs and also injecting flares into empty underground cavities to prevent its release. 
2. Collecting and transporting gas to the natural gas collection facilities and transferring to the gas transmission network. 3. Using the heat of burning gas for the production of hot and steam water and its use in electricity production and urban hot water systems, as well as the direct production of electricity by the gas generator.

4. Use of methane and carbon dioxide gas and heat from burning gas in GTL production processes.

\section{LNG production.}

In the first and second methods, the flare gas is injected into a series of physical separations, or even directly into the desired fields, and is transmitted through the compression process to the gas transmission network. In the third method, the flare gas is burned in a gas combustion engine, and the energy is connected to a generator that generates electricity, as well as, if necessary, the heat from the exhaust, for steam generation and the hot water system It is worth noting that in the method of producing gas from flares, the gas combustion engine is

Figure 1. Station for collecting gas flares of Parsi Square

Figure 2. Gas generator generators specific to burning flare gases, which this the combustion engines are manufactured by the Spanish Gas Company. The first method has recently been implemented in our country, Iran. According to the Shana News Agency, the site of Aka Iran, the Gas Pipeline Gas Pipeline Station of Parsi Square, with a view to preventing burning of at least 3 and a maximum of 7.5 million cubic feet of burning gases daily and preventing environmental pollution, in the oil and gas operation area Aghajari has been utilized. This is the first gas burning program (Figure 1) with participation and participation The private sector has been established and KAMKAB Gas Co. as the executor of this project by building a gas booster unit with a capacity of about 7.5 million cubic feet per day, aggregating the PARSIAN cluster unit's low-pressure gases and burning it prevents the image of the project below.

In the case of the method of generating electricity (Figure 2) of flare gases, the picture is as follows.
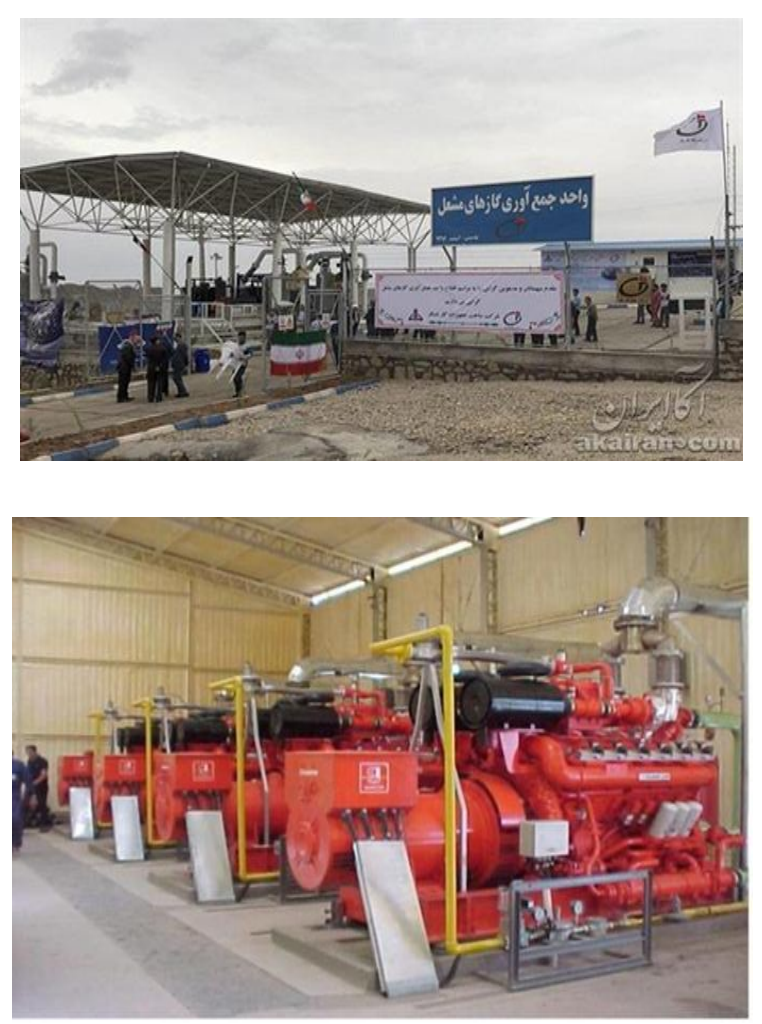
The fourth method, called gas-to-liquid (GTL) (Figure 3), is a refinery process of converting natural gas with other gas hydrocarbons into other hydrocarbons-other chains such as gasoline or diesel fuel [13]. Methane-rich gases are either synthetic fluid fuels or through direct conversion using the new gas technology of the non-catalytic process of gas to liquids that convert methane to methanol in one step or as a synthesis gas mediator, for example With the help of Fisher Trees or accompanying processes, this procedure starts with possible partial oxidation (natural gas) to carbon dioxide, carbon monoxide, hydrogen, and water [14], The ratio of carbon monoxide to hydrogen $\left(\mathrm{H}_{2}\right)$ is adjusted by using water vapor change reactions, while additional carbon dioxide is removed by water from the solution of alkanol (solvent or physical), finally, the gas output Synthesis that reacts chemically. More than one iron or cobalt catalyst for the production of liquid hydrocarbons and other subsidiary products, oxygen is provided from an air cooler separation unit $[15,16]$.

The fifth method of liquid natural gas (LNG) is liquefied natural gas, which is temporarily converted to liquid state for storage or transportation. LNG contains more methane (more than 90\%) and low levels of ethane, propane and butane, and some other heavy alkanes. The LNG refining process can be designed in such a way that the finished product contains $100 \%$ methane. The stages of the LNG production process are as follows:

\section{Sweetening gas}

2. Recovery of acid gas

3. Dewatering

4. Remove mercury

5. Liquefaction

Another method is presented (Figure 4), which is referred to as the Feller Gas Refurbishment System (FGRS) [11], which describes that the aero gases first enter a three-phase, two-phase Oil and water are discharged and the gas phase enters the liquid chromatography system and the rest of the gases are flared $[9,10,12]$.
Figure 3. Fisher's throup process

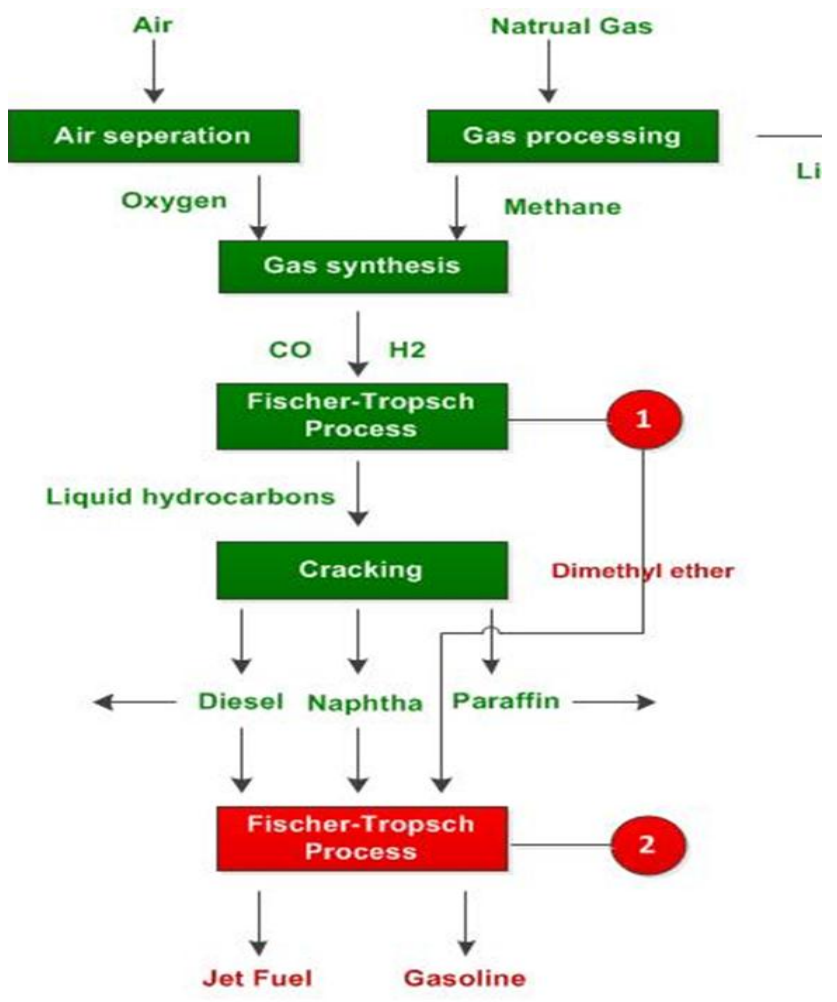

GTL process using the GPS and ZKT.CO method 
Figure 4. Flare gas recovery system

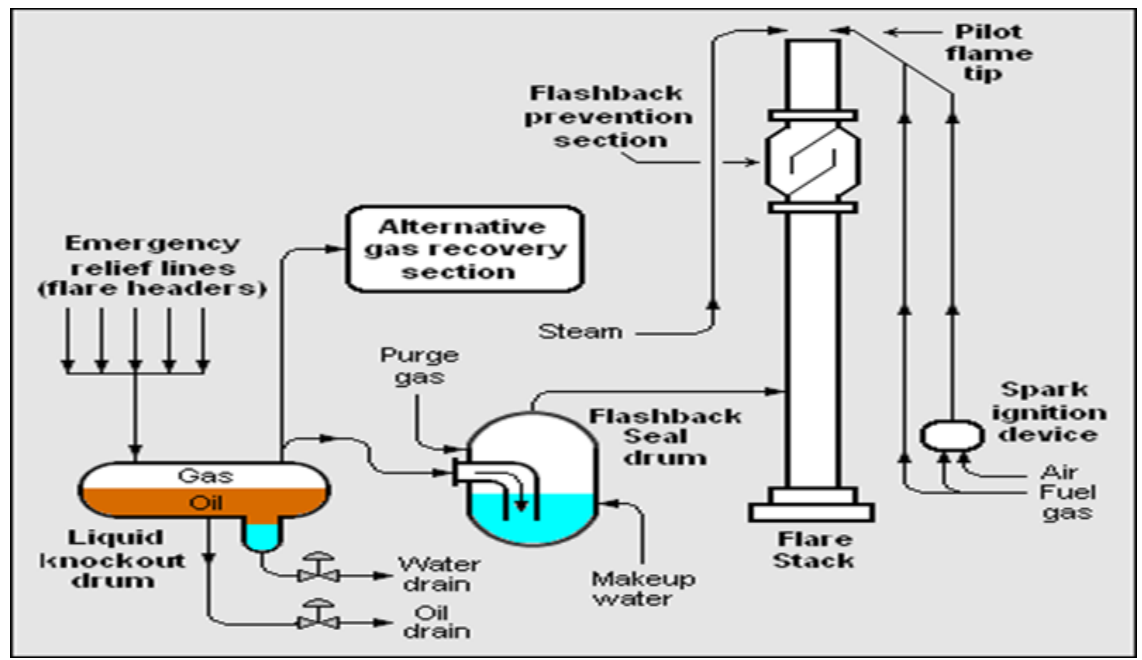

Compressed gases are used internally at the refinery. In this way, of course, it is also used with reciprocating compressors. The advantage of liquid-cycle compressors is the cooling of gases when compressed by the heat transfer of gas to the liquid inside the compressor (usually water). If you want to separate $\mathrm{H}_{2} \mathrm{~S}$ from flare gases, you can use amine instead of water in these compressors $[6,7]$. Reciprocating compressors can be bought more easily than liquid cycle compressors. Repairs and maintenance of this type of compressor are easier. If using reciprocating compressors, it should be noted that if the temperature is too high it is possible to explode. Therefore, it is better to use liquidcycle compressors to improve safety [8].

As for the proposal process, it is as follows:

- Flare Gases Feed Entering (MP \& HP \& LP)

- Separation Lp Flare Line

- Use Same Pressure

- Compressing

- Cooling

- Injection To Sour Gas Line

Phase 12 flare gas lines are classified into three categories of high pressure, medium and low pressure, marked with symbols FA and FC (high pressure), FS (medium pressure) and FB (low pressure). High pressure and medium pressure lines do not need to be isolated due to the amounts of compounds that they require, but in low-pressure lines, they require a preliminary separation according to the amount of compounds. After separating these lines, they are identical with the same pressure, and then compressed with compressed or reciprocating centrifugal compressors, and then compressed to a cooling stage until their temperature to the optimum level. Finally, the flare gases are injected to the desired location with the desired temperature and pressure (the sour gas line) until it reaches the sweetening stage twice.

\section{Result and discussion}

In this section, the economy of gaseous flare has been examined from two perspectives:

- Calculation of the amount of gas from the flare of phase 12 by conversion.

- Calculation of the volumes of flared gases of Phase 12 equivalent to domestic, industrial and export uses.

Calculation of the amount of income of gas flares of phase 12 by conversion

Calculate the molecular weight percentage 


$$
\begin{aligned}
\Rightarrow \quad(3.55 \times 28) & +(0.9 \times 44) \\
& +(86.99 \times 16)+(5.54 \times 30) \\
& +(1.98 \times 44)+(0.32 \times 58) \\
& +(0.25 \times 72) \\
& =99.4+39.6+1391.84 \\
& +166.2+87.12+18.26 \\
& +26.68+18=1847.4
\end{aligned}
$$

Molecular weight of flare gas

$$
M W \text { Gas }=\frac{M W \%}{100}=\frac{1847.4}{100}=18.47
$$

The amount of gas flared in kilograms per hour

$$
\begin{aligned}
\text { Gas flow }=40 & \frac{\text { Ton }}{\mathrm{hr}} \times \frac{1000 \mathrm{~kg}}{1 \mathrm{Ton}} \\
& =40000 \frac{\mathrm{kg}}{\mathrm{hr}}
\end{aligned}
$$

Conversion of kilograms per hour to cubic meters per hour

$$
\frac{40000 \frac{\mathrm{kg}}{\mathrm{hr}} \times 22.4}{18.47}=48500.6
$$

Specific gravity of the flare

$S_{p} G r^{1}=\frac{M W \text { Gas }}{M W \text { air }} \Rightarrow \frac{18.47}{29}=0.63$

${ }^{1}$ Specific gravity

MACLER's method for calculating thermal value

Calculation of net thermal value

$$
\begin{aligned}
N . H . V^{2}=155 & +1425 \times 0.63 \\
& =1052.75 \frac{B t_{u}}{f t^{3}}
\end{aligned}
$$

${ }^{2}$ Net heating value

$$
\begin{aligned}
1052.75 \frac{B t_{u}}{f t^{3}} \times & 8.9 \\
& =9369.47 \frac{\mathrm{KCal}}{M^{3}} \times \frac{4.184 \mathrm{kj}}{1 \mathrm{hcal}} \\
& =39201.88 \mathrm{kj}
\end{aligned}
$$

$\Rightarrow 39201.88 \times 10^{3} \mathrm{j} \times \frac{2.77 \times 10^{-7} \mathrm{kwh}}{1 \mathrm{j}}=$

$10.85 \mathrm{kwh}$ Thermal gas flare worth

If the selected engine efficiency is about $42 \%$ (the ignition engine is flashing gas):

$$
\begin{gathered}
\text { Efficiency }=\frac{P_{\text {out }}}{P_{\text {in }}} \rightarrow 0.42=\frac{P_{\text {out }}}{10.85} \Rightarrow P_{\text {out }} \\
=4.5 \mathrm{kwh}
\end{gathered}
$$

$48500.6 \times 4.5 \mathrm{kwhr}=221196.2 \mathrm{kw}$

The amount of electricity produced in a year

$221196.2 \times 8000=1769569881 \mathrm{kw}$

$123 \times 10^{5}$ DOLLORS

So the value of the price of gasoline flares by turning it into electricity is $\$ 123,125$.

Calculation of the flue gas volume of phase 12 equivalent to domestic, industrial and export consumption

According to the Iranian jubilee news agency, on Sunday, at 23.1.2018, gas consumption reached 639 million cubic meters per day. The statistics in Table 6 are 639 million cubic meters based on calculations and consumption.

Iran's gas consumption on Sunday, at 23.1.2018, was 639 million cubic meters. This amount includes:

industries : $935 \times 10^{5} \frac{\mathrm{m}^{3}}{\text { day }}$

power plants: $151 \times 10^{6} \frac{\mathrm{m}^{3}}{\text { day }}$

Commercial and household: 394

Export: $35 \times 10^{6} \frac{\mathrm{m}^{3}}{d a y}$ 
Considering that the flushed gas phase of the phase 12 is $48560 \mathrm{~m}^{3} / \mathrm{hr}$, this amount is $1165440 \mathrm{~m}^{3}$ per day. So by dividing this amount of gas, we will have the quantities of industrial, power plants, household and commercial parts:

$$
\text { industries: } \begin{gathered}
\frac{1165440 \mathrm{~m}^{3} / \text { day }}{935 \times 10^{5} \mathrm{~m}^{3} / \text { day }} \times 100 \\
=1.24 \%
\end{gathered}
$$

power plants: $\frac{1165440}{151 \times 10^{6}} \times 100=0 / 77 \%$

Commercial and household: $\frac{1165440}{394 \times 10^{6}}$

$$
\begin{gathered}
\times 100=0 / 3 \% \\
\text { Export: } \frac{1165440}{35 \times 10^{6}} \times 100=3 / 3 \%
\end{gathered}
$$

\section{Conclusion}

According to the study, using the MACLER's method, the economic value of the flares gas was converted to electrical energy equivalent to $\$ 123,125$ per year, which is, of course, gross income, and the total volume of flushed gas phase 12 is 3.3\% Exports of gas, $0.3 \%$ of household and commercial sector, $0.77 \%$ of power plant consumption, $1.24 \%$ of industries. In fact, in this study, the economic value of the phase 12 flare gas was converted into electricity, and the flared gases were equated in terms of gas volume with the volume of domestic and industrial gas consumption. This phase alone burns up to $1165440 \mathrm{~m}^{3}$ of gas per day, which is high volume. In the end, these gases will not only pollute and wasting money, but also cause global warming.

\section{List of symbols}

Heat Sensing Unit (English)

Btu

Wet High Pressure Line

FA

Low Pressure

FB
Medium Pressure Flair Line $\quad$ FS

Dry High Pressure $\quad$ FC

Foot $\mathrm{ft}$

Hour hr

Joule j

Kilo calories kcal

Kilo gram kg

Kilo Joule kj

KWh Kwh

Low Pressure LP

Medium Pressure MP

Molecular Weight MW

Input Power (kw) $\quad \mathrm{P}_{\text {in }}$

Output Power (kw) $\quad \mathrm{P}_{\text {out }}$

Indexes

Input In

Output out

\section{Acknowledgements}

I offer the spiritual value of this article to the pure and divine spirit of my mother, the great deeds of my father and my sister, and thanks to Dr. Hamidi's guidance.

\section{References}

[1]. Z. Amini, I. N. H. Saber Application of High Integrity Pressure Protection Systems (HIPPS) for Flare Load Reduction in Jam Gas Refinery, 15th Iranian National Congress of Chimical Engineering, 2015, https://www.civilica.com/Paper-ICHEC15ICHEC15_188.html.

[2]. M. Ashena, H. Sadeghi, K. Yavari, R. Najarzadeh, Int. J. Energy Econ. Policy, 2016, 6, 542-550.

[3]. S.A. Taheri, M.H Dehghan Manshadi, A.R. Arman Moghaddam, Normal Flare Gas Recovery for Iman Khomeini oil Refinery (Phase II)., 4th ${ }^{\text {th }}$ ETEC Conference, emerging Trends In energy Conservation, 2015, 4, 9-10. https://www.civilica.com/Paper-ETEC04ETEC04_006.html

[4]. Assareh, N., Dashti, A., \& Mohebbi, A. Comparative Evaluation of Numerical and 
Gaussian Models for Gas Pollutants Dispersion from Industrial Flares. In The 7th International Chemical Engineering Congress and Exhibition (IChEC 2011), 2011.

[5]. A. Soltani, An Investigation on the Cracks and Hot Corrosion- Like Failures in AISI 310 Flare Tips of South Pars Gas Complex., 5th international conference on engineering Materials and mettalurgy (iMat 2016), 2016. https://www.civilica.com/Paper-IMES10IMES10_168.html

[6]. B.O. Evbuomwan, V. Aimikhe, J.Y. Datong, Europ. J. Adv. Eng. Technology, 2018, 5, 775781.

[7]. M. E., Sangsaraki, E. Anajafi, Design criteria and simulation of flare gas recovery system. In Proceedings of the International Conference on Chemical, Food and Environment Engineering (ICCFEE'15), Dubai, $U A E$ (pp. 11-12), 2015, pp 11-12.

[8]. H. Bakhteeyar, A. Maleki, A. M. Mashat, S. Sattari, Bulg. Chem. Commun., 2016, 48, 333339.

[9]. E. A. Emam, Petroleum \& Coal, 2015, 57(5).

[10]. E. Roger, Flare Gas Recovery System Project Consideration, 4C Environmental Conference, 2015, 1-24

[11]. M. Esmaeili, A. Ghadimi, S. A. Nosrati, Conceptual Evaluation of a Membrane Unit for Flare Gas Recovery: Possibility, Efficiency and Advantages, $12^{\text {th }}$ International Seminar on Polymer Science and Technology, 2016. https://www.civilica.com/Paper-ISPST12-

ISPST12_514.html

[12]. G. Nirmala, L. Muruganandam, Journal of Chemical Reviews, 2019, 1, 114-129.

[13]. (a) S. Lee, J.G. Speight, S.K. Loyalka, Handbook of alternative fuel technologies. CRC Press, 2014; (b) Araújo, K. The emerging field of energy transitions: progress, challenges, and opportunities. Energy Res. Soc. Sci., 2014, 1, 112-121.

[14]. A. D. Hix, M. Moore, R. Kendall, R. Svoboda, W. Maningas, Gas to Liquids (GTL), 2012.
[15]. D.A. Wood, C. Nwaoha, B.F. Towler, J. Nat. Gas Sci. Eng., 2012, 9, 196-208.

[16]. H. Kim, D.A. Boysen, J.M. Newhouse, B.L. Spatocco, B. Chung, P. J. Burke, W. Wei, Chem. Rev., 2012, 113, 2075-2099.

[17]. National Iranian Oil Company, South Pars Gas Field Development Phase 12, Operating Manual for Unit 140, Flares and Blowdown, 2012, pp. 1-10.

\section{How to cite this manuscript: Kiumars}

Hashemi Fard, Mojtaba Shafiee, Recovering Gas Flares from the 12th Gas Phase of the South Pars Gas Refinery, Adv. J. Chem. A, 2020, 3(1), 49-57. 